\title{
Retraction
}

\section{Retracted: Examining Dent Formation Caused by Hailstone Impact}

\section{Shock and Vibration}

Received 28 April 2020; Accepted 28 April 2020; Published 28 August 2020

Copyright (c) 2020 Shock and Vibration. This is an open access article distributed under the Creative Commons Attribution License, which permits unrestricted use, distribution, and reproduction in any medium, provided the original work is properly cited.

Shock and Vibration has retracted the article titled "Examining Dent Formation Caused by Hailstone Impact" [1] at the request of the author, due to significant overlap with a Bachelor of Engineering thesis by Mr. James Maguire [2] on which the author was a co-supervisor and with an M. Phil thesis (in progress) by Mr. Yufei Wu.

\section{References}

[1] M. E. Uz, "Examining Dent Formation Caused by Hailstone Impact," Shock and Vibration, vol. 2019, Article ID 6175206, 16 pages, 2019.

[2] J. Maguire, "Experimental determination of the effects of hail impact on steel building envelopes," in Civil, Mining and Environmental Engineering, pp. 1-108, University of Wollongong, Wollongong, Australia, 2014. 


\title{
Examining Dent Formation Caused by Hailstone Impact
}

\author{
Mehmet E. Uz $\mathbb{D}^{1,2}$ \\ ${ }^{1}$ Lecturer, Department of Civil Engineering, Faculty of Engineering, Adnan Menderes University, Aydin 09100, Turkey \\ ${ }^{2}$ Honorary Research Fellow, School of Civil, Mining and Environmental Engineering, University of Wollongong, Wollongong, \\ NSW 2500, Australia \\ Correspondence should be addressed to Mehmet E. Uz; mehmet.uz@adu.edu.tr
}

Received 14 November 2018; Revised 22 March 2019; Accepted 17 April 2019; Published 16 May 2019

Academic Editor: Nicola Nisticò

Copyright (c) 2019 Mehmet E. Uz. This is an open access article distributed under the Creative Commons Attribution License, which permits unrestricted use, distribution, and reproduction in any medium, provided the original work is properly cited.

\begin{abstract}
Hailstorms pose significant risk for exposed building cladding materials. Steel sheeting is the most important cladding material used. The understanding of steel sheets behavior under hail impact loading is not sufficient for the manufacturing of hail-resistant sheets. With the purpose-built equipment, artificial hailstones of different sizes were launched to impact at steel sheets of different thicknesses and yield stresses as targets. A theoretical approach for the problem of predicting the dent size due to hailstone impact was developed and compared to the test results. The expressions developed in the theory can predict the dent depth before the impact, assuming the ratio between the dent depth and dent diameter is constant. The expression is not able to predict the depth of dents smaller than $0.75 \mathrm{~mm}$ and cannot predict whether the denting will occur or not. All hailstone sizes lead to visible dent on steel sheet of thicknesses $0.35 \mathrm{~mm}, 0.42 \mathrm{~mm}$, and $0.55 \mathrm{~mm}$. Visible denting was also obtained for the $0.75 \mathrm{~mm}$ steel samples with $45 \mathrm{~mm}$ and $55 \mathrm{~mm}$ hailstones; however, no denting occurred using $40 \mathrm{~mm}$ hailstones. It was found that the dent depth was inversely proportional with thickness and yield stress, while the dent diameter was found to be proportional to yield stress. As the yield stress of the steel sheet increased, the dent depth decreased for G300 and G550 steel. The dent diameter however increased as the yield stress increased. When the artificial hailstone shatters on impact, significant energy is lost and less energy is available to cause plastic deformation of the impacted material.
\end{abstract}

\section{Introduction}

Damage associated with hailstorms can be on par with earthquake damage. One-third of total economic losses caused by natural disasters in Australia between 1967 and 2003 were as a result of hailstorms [1-3]. On 14 April 1999, a hailstorm in Sydney became the most costly natural disaster in Australian insurance history, causing a total loss of over AUD2.2 billion, with approximately AUD1.7 billion damage insured. Hailstorms are thought to be more frequent and have greater potential to cause economic damage and injuries in the future as climate change takes its toll [4]. Australian climate models predict hail days to increase by 1 2 days by 2030 and 4-6 days by 2070 [5]. Due to the low risk to life, there are no specifications in the building codes of Australia for building cladding materials to resist hailstorms. A simple increase of the thickness of the steel roofing materials to increase the hail impact resistance was investigated in a report from Bengtsson et al. [6]. In this report, the 162000 houses were assumed to be at risk of hail damage. The change of the thickness of steel roofing panels from $0.40 \mathrm{~mm}$ to $0.55 \mathrm{~mm}$ was calculated to save 200 roofs every year. The change would result in the prevention of AUD55 million and would cost AUD145 million in total. This represents a loss of AUD90 million, indicating that this adaptation to existing housing stock is not economical. The effects of increasing yield stress and optimization of steel sheet profile may see a reduction in implementation cost for dent-resistant roofing without the need to increase thickness.

A hailstone is an ice ball with a diameter greater than $5 \mathrm{~mm}$ [7-10]. Over 75\% of hailstones are spherical, and they are generally found to have densities within the range of $700 \mathrm{~kg} / \mathrm{m}^{3}$ to $910 \mathrm{~kg} / \mathrm{m}^{3}$. Hailstones have a lower density than the pure ice because of the air bubbles trapped within [11-14]. Terminal velocity of spherically shaped hailstones 
was investigated by Laurie [15]. Terminal velocities for different diameter hailstones are shown in Table 1. The use of spherical ice molds monolithically cast with distilled water is specified by the test standards ASTM E822 and FM4473. This method was modified to fill the silicone ice molds in two stages to prevent cracking upon expansion during freezing [14]. The use of layered ice balls was also investigated by comparing the monolithically cast ice balls and horizontally layered ice balls. However, the force imparted on the target material was unaffected by the hailstone casting method [8]. This indicates that the use of horizontal layered ice balls did not influence the simulation capability of monolithically cast ice balls. The measurement techniques for dent penetration and diameter were improved by Long et al. [25] and Lozowski and Strong [16]. In their studies, exact solutions were given to calculate the dent depth and diameter very accurately.

Research on hail impacts on steel is primarily focused on building materials, automotive panels, and aircraft panels. Measurement of hail impact resistance of steel plates usually relies on static or quasi-static loading conditions. Finding the minimum energy required to initiate a dent is the objective of these investigations. American Society for Testing and Materials developed the ASTM D3746. In the test, the hail impact resistance of the specimen is evaluated by dropping $2.27 \mathrm{~kg}$ steel projectile with a $25 \mathrm{~mm}$ radius hemispherical head from a height of $1350 \mathrm{~mm}$ onto the specimens. Another test standard is ANSI/FM 4473, which evaluates impact resistance of the cladding material subject to impact by the spherical ice balls of $31.8 \mathrm{~mm}, 38.1 \mathrm{~mm}$, $44.5 \mathrm{~mm}$, and $50.8 \mathrm{~mm}$. Velocities of the propelled projectiles cause the kinetic energy to exceed a specified target kinetic energy by less than $10 \%$. The use of kinetic energy as a parameter for assessing hailstone impacts has not been adequately investigated and assumes a proportional relationship between the hailstone mass and velocity squared. The uncontrollability of the loss of energy and energy transferred to the specimen is also difficult. Researchers have provided several ways to simulate hail impact to assess impact resistance. This study aims to develop a method to measure hail impact resistance and to examine the effects of hailstone impact. A testing method was developed by $\mathrm{Uz}$ et al. $[9,17]$ for the bachelor thesis of Maguire in the University of Wollongong in Australia and is now going to be used in this study [18].

\section{Dent Resistance of Steel Sheets}

Impact resistance, particularly dent resistance, of the steel sheet is its ability to resist denting under impact loading. Efforts have been made to test the impact resistance statically due to relative simplicity to conduct tests and the reproducibility of the tests. Dynamic testing, however, simulates the real conditions much better. The energy to produce a $0.1 \mathrm{~mm}$ dent in car door panels and stretched dome panels increased with increasing load rate [19]. Therefore, as the inertial effects of the impact increase, an increase in dent resistance can be observed. This test was carried out from a quasi-static to dynamic loading of up to
TABLE 1: Terminal velocity for hailstones of various diameters given by Laurie [15].

\begin{tabular}{lcc}
\hline Diameter $(\mathrm{mm})$ & $\begin{array}{c}\text { Terminal velocity } \\
(\mathrm{m} / \mathrm{s})\end{array}$ & $\begin{array}{c}\text { Approximate impact } \\
\text { energy }(\mathrm{J})\end{array}$ \\
\hline 25 & 22.3 & $<1.4$ \\
32 & 25.0 & 5.4 \\
38 & 27.4 & 10.9 \\
45 & 29.6 & 19.0 \\
\hline & &
\end{tabular}

$26.8 \mathrm{~m} / \mathrm{min}$. Through dynamic testing using a pneumatic gun and steel indenter, Burley et al. [19] found that dynamic denting was related to panel thickness, yield stress, modulus of elasticity, density, and panel shape. A decrease in panel stiffness of bake hardened steel was found to result in an increase in dynamic dent resistance [20]. The results are not reflected in the same paper between the results of dynamic loading and static loading, where the dent resistance was found to increase with increasing panel stiffness. Holmberg and Thilderkvist [21] have found that the increase in yield stress due to work hardening from the application of 2-5\% strain on mild steel panels increased the dent resistance $20 \%$ despite the associated thickness reduction. Two empirical formulas to estimate the denting force and denting energy required to produce a visible dent was presented by Shi et al. [22]. The denting force, $F_{\mathrm{d}}$, was given as follows:

$$
F_{\mathrm{d}}=K_{\mathrm{S}_{1}} \sigma_{\mathrm{Y}}^{0.718} t^{0.5}
$$

where $K_{\mathrm{S}_{1}}$ is a constant found to be 17.78 for the units $\mathrm{MPa}$ and $\mathrm{mm}$. The energy required to produce a visible dent, $W_{0}$, was given as follows:

$$
W_{0}=K_{\mathrm{S}_{2}} \sigma_{\mathrm{Y}}^{0.915} t^{0.322},
$$

where $K_{S_{2}}$ is a constant found to be 0.005 for the units $\mathrm{MPa}$ and $\mathrm{mm}$. The experimentation was carried out by dropping a weight. The indenter was a steel tipped dart.

\section{Theoretical Aspects}

The study aims to assess the hailstone impact resistance of the steel sheets by developing an equation to give the dent depth and diameter. Results obtained from the theoretical equation will be compared to the results obtained from experiments. The experiment arrangement used to conduct tests allows the artificial hailstones of various sizes to be propelled at desired velocities striking steel sheets of various yield strengths and thicknesses. Bircan et al. [18] mentioned that the key factor in the hail resistance assessment of building materials is the velocity measurement equipment. In the study of Bircan et al. [18], the laser sensors were not enough to measure the velocity of hailstones. Hence, in this study, the flight and impact of the projectile is recorded with a high-speed camera. The camera also helps to capture the simulation of artificial hailstone on impact whether it is shattered or intact. The final dent depth and diameter are recorded. To analyze the data, some assumptions and generalizations are made. 
3.1. Dynamic Hail Impact Test Equipment. The test scheme of the study relies on pneumatic propulsion of artificial hailstones. The test scheme can be used for propelling other objects onto other specimens as well. The purpose-built test scheme mainly consists of the hail launcher, protective unit, and recording devices. The experiment was conducted parallel to the ground, as given in Figure 1. Mounting the pneumatic gun vertically was not found to result in significant benefits [23]. On the contrary, mounting the pneumatic gun in a vertical manner would make the test scheme more complicated and increase the safety hazards. The horizontal test scheme was used successfully by several researchers $[7,8,14,24-26]$. For the support system (boundary condition), the steel sheeting is screwed to timber battens spaced at $600 \mathrm{~mm}$ from each other and the projectile is aimed perpendicularly at the middle between the two battens. According to Kim et al. [27], the boundary condition does not strongly change the dynamic dent resistance even if it affects the stiffness. Juntikka and Olsson [28] stated that the force generated during the dynamic impact is independent of the boundary conditions as the impact is localized. The artificial hailstones used in the study are monolithically cast spherical pure ice balls of various diameters. Ice balls are chosen as artificial hailstones as pure ice can be close to the densities of the natural hailstones, and they display the surface melting behavior observed in natural hailstones. For all cases, the freezer temperature is remained at $-12^{\circ} \mathrm{C}$. Based on the rate of melting recording during this study, no loss of mass occurred between the initial recording and the recording at two minutes for nominal diameter 40 , 45 , and $55 \mathrm{~mm}$ hailstones. Therefore, hailstones were stored at ambient temperature for no more than two minutes before testing to reduce melting and maintain accuracy of results. Hail launcher consists of air compressor, regulator, barrel, gas valve, hail holder, and pneumatic gun mount.

Compressor was used to provide the necessary pneumatic pressure in order to propel the projectile. Regulator allows for measuring the correct pressure for the desired velocity. Receiver holds the pressure until firing the gun, having a safety valve to relieve the compressed air based on the AS 1210 standard for pressure vessels. Barrel had a hollow smooth bore steel cylinder wide enough to fire projectiles of different sizes. A ruler was attached at the end of the barrel to allow velocity measurement. Gas valve acts as a trigger to fire the projectile. Holder was placed before the ice ball to act as a sabot, preventing the ice ball to be damaged while exiting the barrel. The gun is fixed on the mount, which allows the gun to be moved easily without disassembling. Protective unit is a box-shaped structure that allows for propelling the ice balls in a safe manner while also acting as a mounting frame for the steel samples. It provides a physical barrier for ricocheting projectiles and fragments. The walls of the protective unit are manufactured from plywood laminated with acoustic insulation, providing some degree of noise reduction from the barrel of the gun and impact onto specimens. One side of the unit acts as a door to allow access inside, and the other side has a glass window that allows the impact and travel of projectiles to be observed and recorded. The unit has two rows of six access holes to fire at different places of the steel sheet without detaching and reattaching the steel sheet to the mounting frame. Recording devices are a high-speed camera and the lighting necessary to use the camera effectively. Impacts are recorded at 1000 frames per second.

3.2. Steel Samples. Steel samples used in the study were selected to provide a variety of target panels, but the choices were limited due to availability locally. Two steel grades are selected: G300 and G550 (manufactured to AS 1397-2011). Data given by manufacturer for the yield strengths of $300 \mathrm{MPa}$ and $550 \mathrm{MPa}$, respectively, were assumed to be correct. The thickness of the steel samples varied between $0.35 \mathrm{~mm}$ and $1.0 \mathrm{~mm}$. The steel samples used in the test are listed in Table 2. In the absence of tensile testing on all steel samples, it was necessary to use the nominal yield strength of the steel material for analysis although elongations at fracture over $15 \mathrm{~mm}, 25 \mathrm{~mm}$, and $50 \mathrm{~mm}$ gauge lengths and uniform elongation outside the fracture $\varepsilon_{15}, \varepsilon_{25}, \varepsilon_{50}$, and $\varepsilon_{\text {uo }}$ of the steel materials were later on obtained for some samples given in Table 3. The measured yield strengths for both materials are now available and significantly higher than the nominal yield strength during the revision process of this paper. Six $12.5 \mathrm{~mm}$ wide tension coupon tests were conducted to provide the yield stress of each type of sheet steels. Half of the specimens were tested in the rolling direction of the steel sheet (denoted with prefix "L" in Table 4) and the other half in the direction perpendicular to the rolling direction (denoted with prefix " $\mathrm{T}$ " in Table 4). The stroke rate was taken as $1 \mathrm{~mm} /$ minute. Six tests were conducted on each steel sheet, with artificial hailstones of $40 \mathrm{~mm}, 45 \mathrm{~mm}$, and $55 \mathrm{~mm}$ in diameter. All testing would be carried out with perpendicular impacts. Tests were labeled as follows: (steel thickness $(\mathrm{mm})$ )/(steel nominal yield stress $(\mathrm{MPa})) /($ hailstone nominal diameter $(\mathrm{mm})$ ) (test number). For example, a test using the $0.35 \mathrm{~mm}$ thick G550 steel sample with a $55 \mathrm{~mm}$ hailstone at $0^{\circ}$ pitch (degrees from perpendicular) would be labeled: 0.35/550/55 (1). Another test using the same parameters would be labeled $0.35 / 550 / 55$ (2). A total of 36 tests would be conducted.

3.3. Assumptions Applied. To develop a theory giving the dent depth and diameter of a hailstone of a known size, some generalizations and assumptions are made to simplify the process. These are as follows:

(1) A constant proportion of kinetic energy in the hailstone is converted into work that is denting the steel sheet

(2) Dents in the steel sheet are in the shape of a spherical cap

(3) No strain occurs in the outside of the dented area

(4) Uniform strain occurs throughout the dented area

(5) Stress-strain behavior of the steel is elastic-perfectly plastic

(6) Thickness of the steel is uniform throughout the dented area 


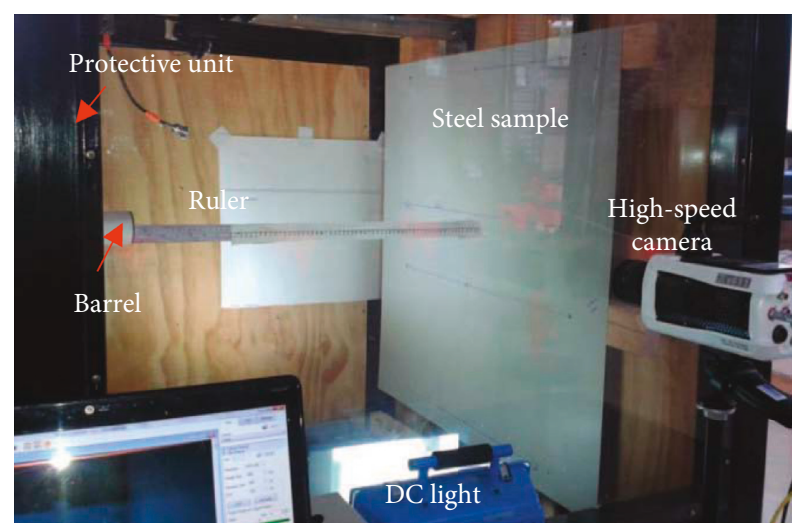

(a)

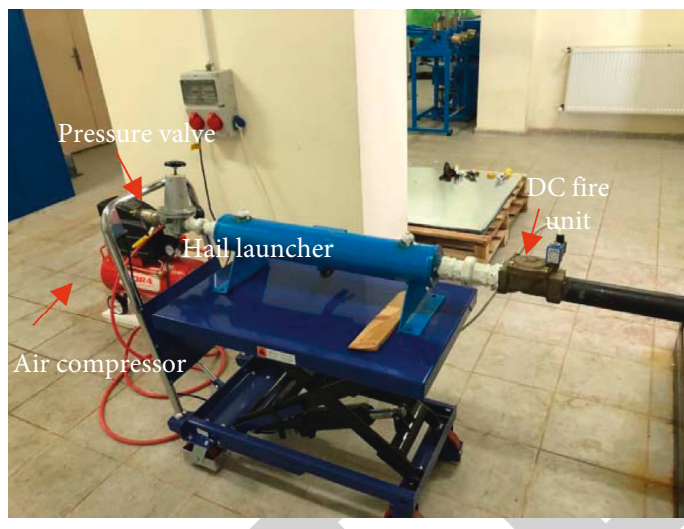

(b)

Figure 1: Experimental set up.

TABLE 2: Steel samples used in this study.

\begin{tabular}{lcc}
\hline Steel grades & Thickness $(\mathrm{mm})$ & Number of sheets \\
\hline G300 & 0.35 & 1 \\
G300 & 0.55 & 3 \\
G550 & 0.35 & 4 \\
G550 & 0.42 & 4 \\
G550 & 0.75 & 4 \\
G550 & 1.0 & 4 \\
\hline
\end{tabular}

TAвLE 3: Average material properties of G550 and G300 steel sheets with the thickness of $0.55 \mathrm{~mm}$ and $1.00 \mathrm{~mm}$, respectively.

\begin{tabular}{lcccccccc}
\hline Grade & Measured thickness, $t(\mathrm{~mm})$ & $\sigma_{\mathrm{y}}(\mathrm{MPa})$ & $\sigma_{\mathrm{u}}(\mathrm{MPa})$ & $\sigma_{\mathrm{u}} / \sigma_{\mathrm{y}}$ & $\varepsilon_{15}(\%)$ & $\varepsilon_{25}(\%)$ & $\varepsilon_{50}(\%)$ & $\varepsilon_{\mathrm{uo}}(\%)$ \\
\hline G300 & 1.01 & 397 & 448 & 1.13 & 43.6 & 36.7 & 27.5 & 22.9 \\
G550 & 0.55 & 731 & 753 & 1.03 & 9.22 & 5.80 & 2.97 & 1.85 \\
\hline
\end{tabular}

TABLE 4: Measured yield stresses of G550 and G300 steel sheets.

\begin{tabular}{lccccccc}
\hline Grade & $\sigma_{y}-L_{1}(\mathrm{MPa})$ & $\sigma_{\mathrm{y}}-L_{2}(\mathrm{MPa})$ & $\sigma_{y}-L_{3}(\mathrm{MPa})$ & $\sigma_{\mathrm{y}}-T_{1}(\mathrm{MPa})$ & $\sigma_{\mathrm{y}}-T_{2}(\mathrm{MPa})$ & $\sigma_{\mathrm{y}}-T_{3}(\mathrm{MPa})$ & Average $(\mathrm{MPa})$ \\
\hline G300_0.35 mm & 278 & 310 & 301 & 314 & 281 & 320 & 301 \\
G300_0.55 mm & 328 & 268 & 314 & 362 & 337 & 285 & 316 \\
G550_0.35 mm & 568 & 652 & 588 & 623 & 654 & 623 & 618 \\
G550_0.42 mm & 652 & 647 & 619 & 654 & 706 & 620 & 650 \\
G550_0.75 mm & 692 & 693 & 714 & 745 & 735 & 727 & 689 \\
G550_1.00 mm & 589 & 544 & 650 & 631 & 655 & 626 \\
\hline
\end{tabular}

The first assumption is necessary to determine the energy available to deform the steel sheet. Hailstone kinetic energy that is not transferred to the steel sheet is lost through other mechanisms such as noise and heat. This would be very minimal in this study. Kinetic energy may be retained in the fractures of the hailstone if the hailstone is broken during impact. Kinetic energy will also be retained as the hailstone rebounds from steel sheet. Further energy losses will occur through the elastic deformation from the impact point to the boundaries of the steel sheet. To account for the energy loss, an energy loss coefficient, $C_{e}$, is applied to the hailstone kinetic energy. Two parameters were defined to describe the dent shape: average dent diameter, $D_{\mathrm{d}}$, and dent depth, $D_{\mathrm{z}}$. The dent shape was assumed to be spherical cap, as shown by the dent cross section in Figure 2, for the analysis. The dent depth, $D_{\mathrm{z}}$, and dent average radius, $r_{\mathrm{d}}$, are shown in Figure 2 . Dent radius is the half of the average dent diameter. It can be assumed that the dent shape is a spherical cap as the sphere radius, $r^{\prime}$, is greater than dent depth, $D_{\mathrm{z}}$. All assumptions are made to make the study easier while interfering with real conditions as little as possible. Hailstones were made in a roughly spherical shape. However, several samples contained notable irregularities. The one having the formation of fractures during freezing was not used in the test. After using finger smoothing to remove any air bubbles trapper near the mold hole, mass and diameter of hailstones were recorded. The surface area of the dent, assuming it is a spherical cap, in three dimensions is given by the following equation: 


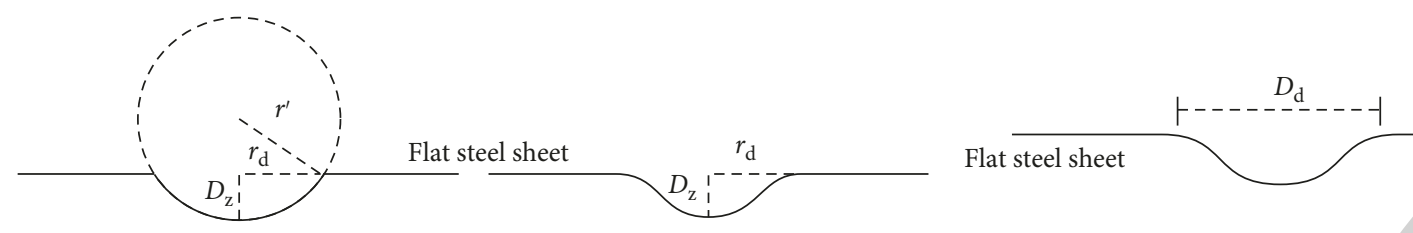

Figure 2: Cross section of dent depth and diameter.

$$
A_{\mathrm{d}}=\pi\left(r_{\mathrm{d}}^{2}+D_{\mathrm{z}}^{2}\right)=\pi\left(\frac{D_{\mathrm{d}}^{2}}{4}+D_{\mathrm{z}}^{2}\right)
$$

Change in area over the initial area gives the final strain of the material where denting has occurred. Initial area is given by the diameter of the initially flat section, which is

$$
A_{0}=\frac{\pi D_{\mathrm{d}}^{2}}{4}
$$

Therefore, material strain is

$$
\varepsilon_{\mathrm{d}}=\frac{\pi\left(\left(D_{\mathrm{d}}^{2} / 4\right)+D_{\mathrm{z}}^{2}\right)-\left(\left(\pi D_{\mathrm{d}}^{2}\right) / 4\right)}{\left(\left(\pi D_{\mathrm{d}}^{2}\right) / 4\right)}=\left(\left(2 D_{\mathrm{z}}\right) / D_{\mathrm{d}}\right)^{2} \text {. }
$$

Steel stress-strain behavior is used to determine the work done per unit volume of material to achieve the final strain, $\varepsilon_{\mathrm{d}}$, after denting. Assuming that the material is elasticperfectly plastic, Figure 3 shows the stress-strain behavior during denting. $\sigma_{\mathrm{y}}$ is the material yield stress, $E$ is the material modulus of elasticity, and $\varepsilon_{\mathrm{E}}$ is the elastic strain. The work done during denting per unit volume of material is shown by the shaded area in Figure 3 and is given by the following equation:

$$
\frac{W_{\mathrm{d}}}{A_{\mathrm{o}} t}=\left(\varepsilon_{\mathrm{d}}+\varepsilon_{\mathrm{E}}\right) \sigma_{\mathrm{y}}-\frac{1}{2} \varepsilon_{\mathrm{E}} \sigma_{\mathrm{y}}=\left(\varepsilon_{\mathrm{d}}+\frac{1}{2} \varepsilon_{\mathrm{E}}\right) \sigma_{\mathrm{y}} .
$$

Elastic strain, $\varepsilon_{\mathrm{E}}$, is given by

$$
\varepsilon_{\mathrm{E}}=\frac{\sigma_{\mathrm{y}}}{E} .
$$

If equations (4), (5), and (7) were substituted into equation (6), the expression for the work required to create a dent in a flat steel sheet is given as follows:

$$
W_{\mathrm{d}}=\left(\left(\frac{2 D_{\mathrm{z}}}{D_{\mathrm{d}}}\right)^{2}+\frac{\sigma_{\mathrm{y}}}{2 E}\right) \frac{\pi D_{\mathrm{d}}^{2} \sigma_{\mathrm{y}} t}{4} \text {. }
$$

Hailstone kinetic energy provides the work required to create a dent, of diameter $D_{\mathrm{d}}$ and depth $D_{\mathrm{z}}$. The proportion of kinetic energy, $E_{\mathrm{k}}$, that is converted into dent deformation is assumed to be a constant factor $C_{\mathrm{e}}$. Therefore,

$$
W_{\mathrm{d}}=C_{\mathrm{e}} E_{\mathrm{k}} \text {. }
$$

Hailstone kinetic energy is given by the following expression:

$$
E_{\mathrm{k}}=\frac{1}{2} m v^{2}
$$

Substituting and rearranging equations (8) and (10) into equation (9) would give the following relationship. The theory has three expressions. First one gives the dent depth

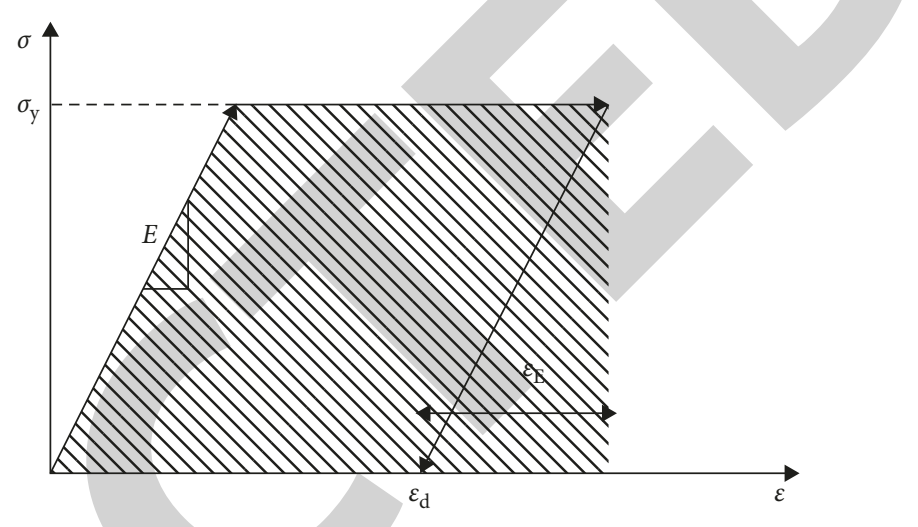

FIGURE 3: Behavior of stress-strain during denting.

with the dent diameter as an input variable. Second one gives the dent diameter with dent depth as an input variable. Third one gives the dent depth with the ratio of dent diameter to dent depth as an input variable:

$$
\begin{aligned}
& D_{\mathrm{z}}=\sqrt{\frac{C_{\mathrm{e}} m v^{2}}{2 \pi \sigma_{\mathrm{y}} t}-\frac{D_{\mathrm{d}}^{2} \sigma_{\mathrm{y}}}{8 E}}, \\
& D_{\mathrm{d}}=\sqrt{\frac{8 E}{\sigma_{\mathrm{y}}}\left(\frac{C_{\mathrm{e}} m v^{2}}{2 \pi \sigma_{\mathrm{y}} t}-D_{\mathrm{z}}^{2}\right)} .
\end{aligned}
$$

Equations (11) and (12) have a limited versatility as they have two unknown variables, $D_{\mathrm{z}}$ and $D_{\mathrm{d}}$, respectively, which are either the dent depth or diameter that must be known in order to determine the other. Equation (11) can be rewritten as

$$
D_{\mathrm{z}}=\sqrt{\frac{C_{\mathrm{e}} m v^{2}}{2 \pi \sigma_{\mathrm{y}} t\left(1+\left(\sigma_{\mathrm{y}} / 8 E\right)\left(D_{\mathrm{d}} / D_{\mathrm{z}}\right)^{2}\right)}}
$$

A solution for the dent depth is allowed if the ratio of dent diameter over dent depth is assumed to be constant. The dent depth can be predicted for a given steel sample under the impact of a given hailstone at terminal velocity.

\section{Results and Discussion}

After comparing the results from the tests and the theory, several conclusions have been drawn in Table 5. Several results were not taken into consideration, and some conditions were not tested. A difference between naturally formed hailstones and artificial hailstone made of monolithically cast pure ice was observed. 


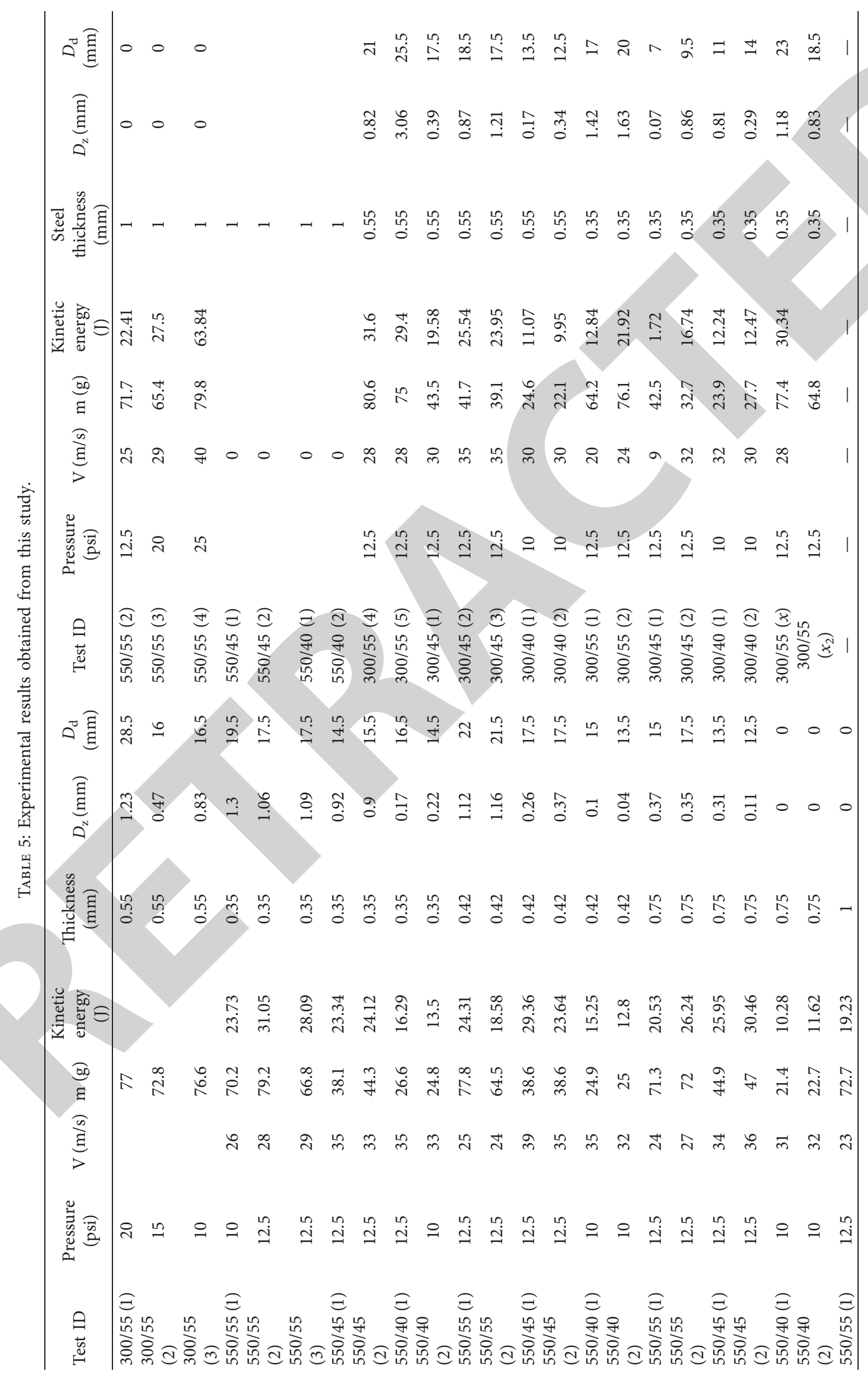




\subsection{Comparison of Naturally Formed Hailstones and Artificial} Hailstones. It is not uncommon to see hailstone bouncing off the surfaces during a hailstorm. Because hail freezes from the inside out, a strong and complex shell structure is formed. The term hail is used when ice particles are larger than $5 \mathrm{~mm}$ in diameter, with smaller particles being classified as ice pellets [10]. Such behavior was observed in the test with relatively small and often large hailstones. Artificial hailstones freeze from the surface to the inside instead of the inside to the surface as seen in natural hailstones. A hailstone was removed from the freezer before it was completely frozen to confirm this. The interrupted hailstone was frozen around the surface while entire core of the hailstone was still in a liquid state.

Artificial hailstones are not as resistant to fracturing as their natural counterparts. The reason is thought to be the formation of fractures during freezing. These fractures may have been caused by the expansion of the core during freezing causing a tensile stress to be applied to the frozen. In addition to having a fractured surface, the artificial hailstones, shown in Figure 4, have a white opaque area offset from the center of the hailstones and caused entrapped air which cannot escape the mold or the outer shell during freezing. Natural hailstones also contain entrapped air, but the distribution is more evenly distributed than artificial ones. The trapped air in the artificial hailstones was confined to a local area, creating a weak point. Due to the weak point on the surface, the artificial hailstones were observed to fracture on impact with the steel sheets. Fracturing of the projectiles caused a loss of energy that could have been transferred to the steel sheet that would have caused a greater dent size. With the use of a high-speed camera, fracturing of hailstones could be observed at 1000 frames/s. In Figure 5, the hailstone can be seen breaking apart. The outer part breaks into pieces up to a tenth of its original size. The inner part shatters into even smaller pieces. Upon shattering, the fragments dispersed in a radial pattern perpendicular to the hailstones initial motion. This behavior is shown in Figure 5 and was observed in the tests but one when the hailstone (Test 0.55/300/55 (5)) bounced off the steel plate intact and as relatively large dent was observed in.

4.2. Dent Depth. True yield stress of the steel sheets should be greater than the nominal value provided. Error was reduced to some degree with the use of the energy loss coefficient, which scaled to the experimental results. Despite the presence of a few errors, a high degree of accuracy is not needed for the practical application of results as the yield stress of steel sheets used for building cladding can vary and only nominal values are used for calculations. The average value between the yield stresses measured in the rolling direction and in the perpendicular direction of each steel sheet given in Table 4 is now used in the related calculations. Dent depths of all the $550 \mathrm{MPa}$ steel sheets are shown in Figure 6. For the thicknesses $0.35 \mathrm{~mm}, 0.42 \mathrm{~mm}$, and $0.75 \mathrm{~mm}$, the dent depth decreases with decreasing hailstone diameter as expected. Additionally, the depths were to be inversely to the sheet thickness. 0.75/45 (2) (kinetic energy is
30.6 joule, while the hailstone mass was $47.0 \mathrm{~g}$ ) has $0.11 \mathrm{~mm}$ dent depth, while $0.42 / 45$ (2) (kinetic energy is 29.36 joule, while the mass was $38.6 \mathrm{~g}$ ) has $0.26 \mathrm{~mm}$ dent depth as a number of other tests with similar variations in test variables still showed consistent dent depths. The specimen $0.75 / 45$ (1) has 20.53 joule of kinetic energy on impact with the mass of $44.9 \mathrm{~g}$, while $0.42 / 45$ (1) specimen has 23.64 joule with 38.6 g.mass. Hence, the repeated tests of the related steel samples with the same nominal size hailstone had the same dent depth recorded as $0.37 \mathrm{~mm}$. A good degree of exit velocity control was not achievable through control of the air receiver pressure using the hollow steel barrel for the specimen named $0.42 / 45$ (1) having the velocity more than its terminal velocity. No visible denting occurred on 1.00 thick steel sheet with tests performed with four $55 \mathrm{~mm}$ hailstones. Given that the largest diameter hailstone was not able to produce a dent, no further tests with lower diameter hailstone were conducted. Similar trends were observed with $300 \mathrm{MPa}$, as shown in Figure 7, steel sheet with the exception of two outliers. Dent depths of the $300 \mathrm{MPa}$ steel sheets were found to be less consistent when compared to the dents observed in $550 \mathrm{MPa}$ steel sheets. Two tests $0.55 / 300 / 45$ (3) and $0.55 / 300 / 45$ (1), despite being tested with hailstones of same nominal size and steel sheet thickness, dent depths were $1.21 \mathrm{~mm}$ and $0.39 \mathrm{~mm}$, respectively. The hailstone masses were $39.1 \mathrm{~g}$ and $43.5 \mathrm{~g}$, while the velocities were $35 \mathrm{~m} /$ $\mathrm{s}$ and $30 \mathrm{~m} / \mathrm{s}$, respectively. Large differences with dent depths here were unexpected as a number of other tests with similar variations in the test variables still showed consistent dent depths. For example, tests 0.35/300/55 (1) and 0.35/300/55 (2) produced $1.42 \mathrm{~mm}$ and $1.63 \mathrm{~mm}$ dent depth, respectively. The hailstone masses were $64.2 \mathrm{~g}$ and $76.1 \mathrm{~g}$, and the velocities were $20 \mathrm{~m} / \mathrm{s}$ and $24 \mathrm{~m} / \mathrm{s}$, respectively.

Test $0.55 / 300 / 55$ (5) produced the larger dent depth of all the tests conducted. In the test, the hailstone remained intact instead of shattering upon impact as was the case with other hailstones in the study. A dent depth of $3.06 \mathrm{~mm}$ was recorded. The same steel sample was tested with another $55 \mathrm{~mm}$ hailstone which shattered on impact like the majority of hailstones. The dent depth was $0.82 \mathrm{~mm}$. Comparison of the dent depths of the $550 \mathrm{MPa}$ and the $300 \mathrm{MPa}$ steel sheets of $0.35 \mathrm{~mm}$ thickness shows that dent depth is reduced as the yield stress increases for both the $55 \mathrm{~mm}$ and $40 \mathrm{~mm}$ hailstones. This can be seen in Figure 8. However, it was found that the two tests performed with $45 \mathrm{~mm}$ hailstone produced lower dent depths in $300 \mathrm{MPa}$ steel sheet than $550 \mathrm{MPa}$ steel sheet. Dent depth of $0.07 \mathrm{~mm}$ was obtained in the test 0.35 / $300 / 45$ (1). This result is inconsistent with other results and is possibly unreliable.

4.3. Dent Diameter. Measurement of the dent diameter was done by taking the average value of two perpendicular measurements: horizontally and vertically across the steel sheets. The measurement was taken from the farthest two points between which permanent deformation has occurred, as shown in Figure 2. The measurement, however, involved a degree of subjectivity as the point where the permanent deformation began was not always clear. In such cases, the 


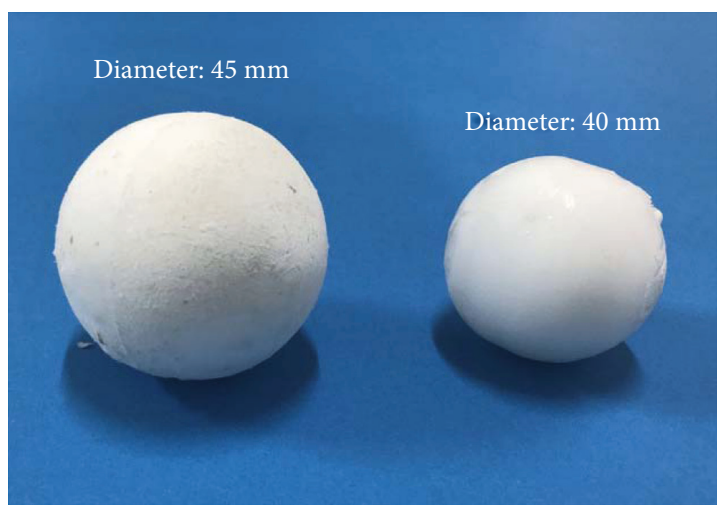

(a)

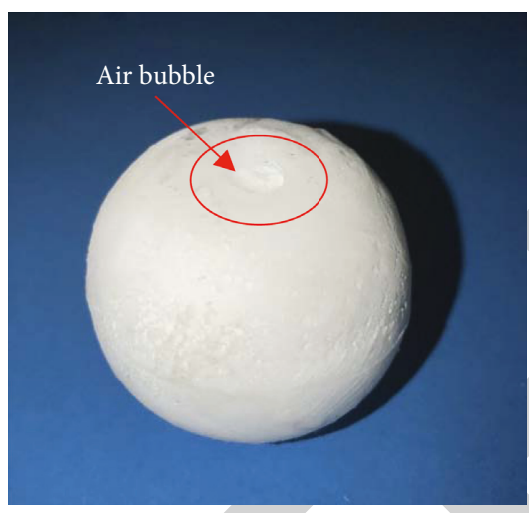

(b)

Figure 4: Artificial hailstone surface cracking.

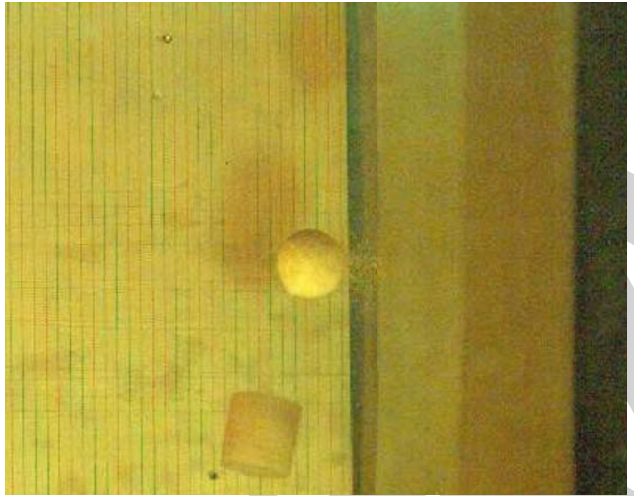

(a)

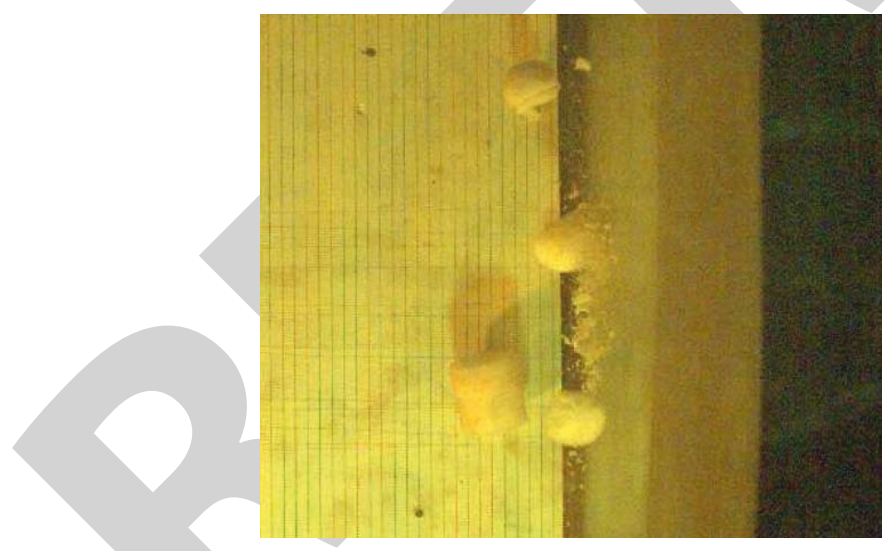

(c)

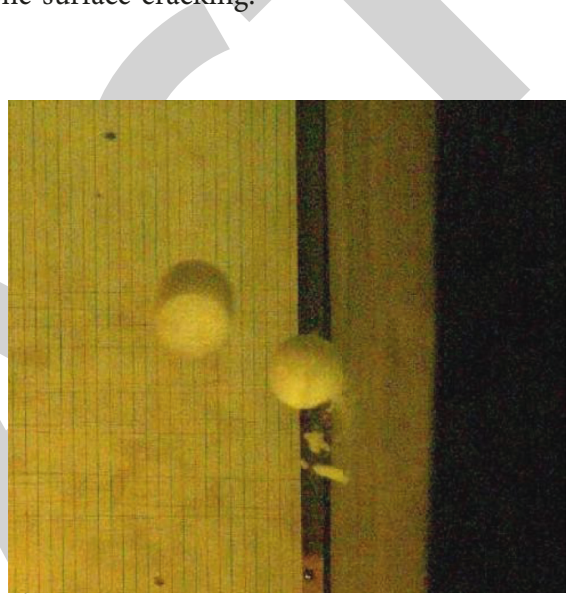

(b)

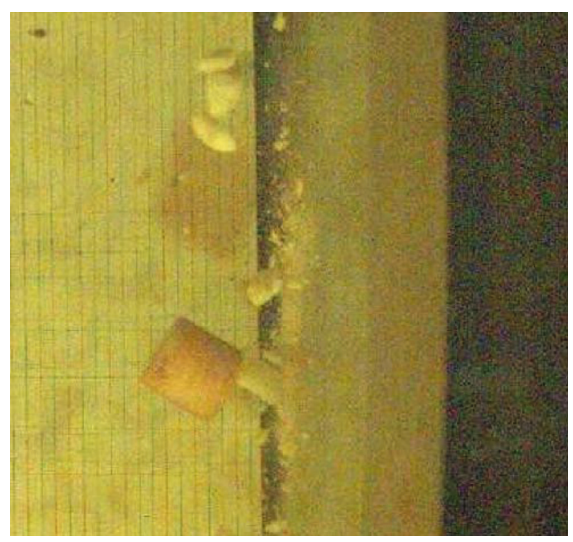

(d)

FIGURE 5: Hailstone on impact: (a) intact; (b) minor; (c) major break; (d) shattering.

values were taken to nearest millimeter accuracy. To reduce the impact of subjectivity on the recorded measurement, the calipers used were opened much wider than the dent diameter and reduced down to the diameter for each measurement. This prevented any visual guesses from being based on previous measurements. Additionally, dent diameter is not as great of a concern as the dent depth, when the cosmetic appearance is considered. Some assumptions were applied to simplify the data analysis due to the many variables involved. The effects of hailstone size, steel thickness, and steel yield stress were investigated. All other variables were assumed to be constant. Hailstone velocity was also assumed to be constant. Velocity of $30 \mathrm{~m} / \mathrm{s}$ was targeted as it was found to be the terminal velocities of the hailstones of tested sizes, and the velocity was achievable with the test scheme. However, velocity varied among tests. This was considered for individual tests where the velocity was significantly different from the target velocity of $30 \mathrm{~m} / \mathrm{s}$. 

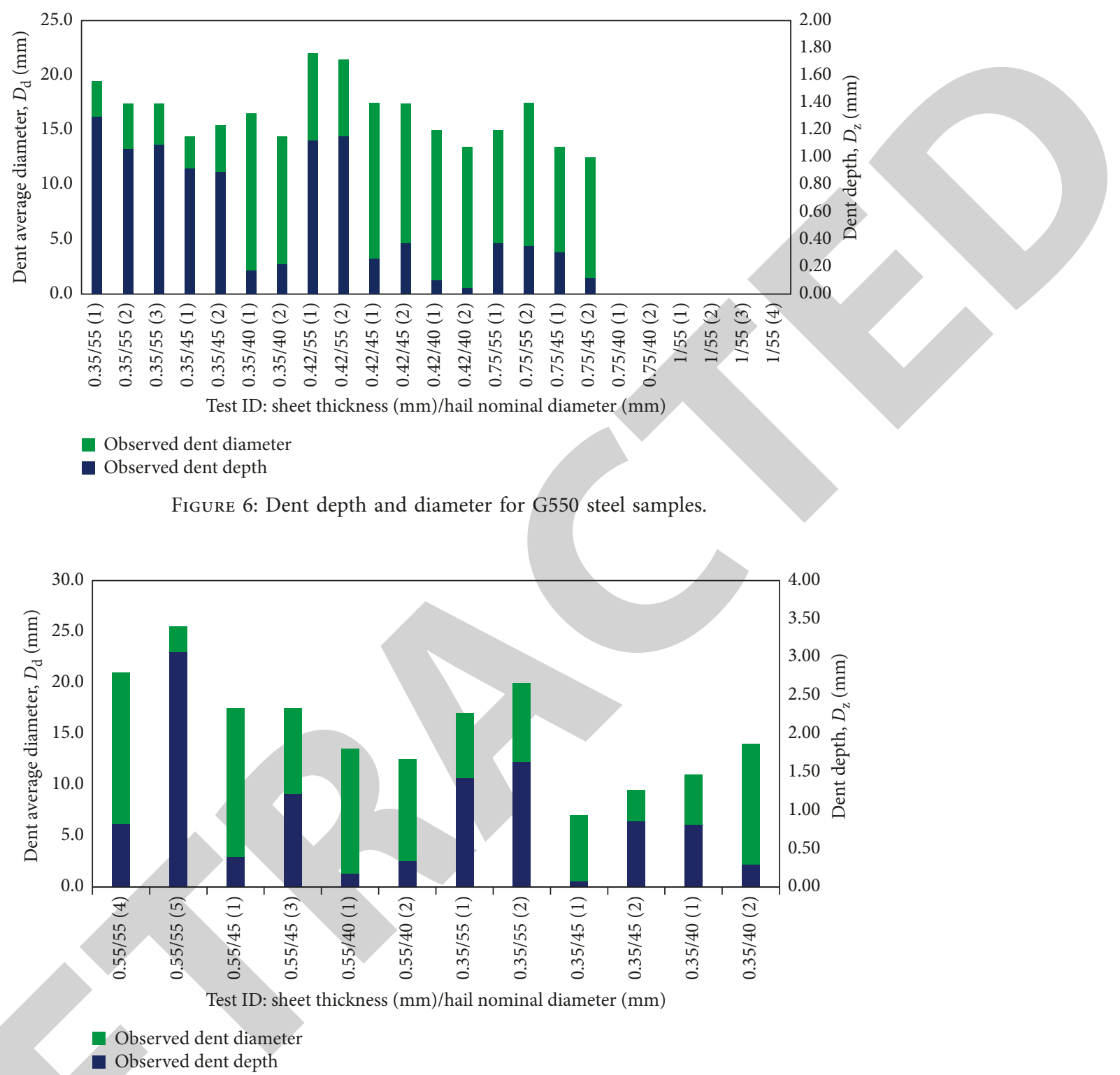

FIGURE 7: Dent depth and diameter for G300 steel samples.

General trends were identified assuming a constant velocity though. Experimental velocities were used in the calculations to discard this assumption from the comparison of theory and experimental results.

The average dent diameter for the $550 \mathrm{MPa}$ steel sheets was proportional to the hailstone size for thicknesses of $0.42 \mathrm{~mm}$ and $0.75 \mathrm{~mm}$, as shown in Figure 6. However, for the $0.35 \mathrm{~mm}$ thick sheet, the trend is not as obvious. On the $0.35 \mathrm{~mm}$ thick steel plate, the average dent diameters for the $40 \mathrm{~mm}$ hailstones were $16.5 \mathrm{~mm}$ and $14.5 \mathrm{~mm}$; for $45 \mathrm{~mm}$ hailstones, $14.5 \mathrm{~mm}$ and $15.5 \mathrm{~mm}$; and for $55 \mathrm{~mm}$ hailstones, $19.5 \mathrm{~mm}$ and $17.5 \mathrm{~mm}$. Dents caused by the $40 \mathrm{~mm}$ hailstones were observed to be larger than dents caused by the $45 \mathrm{~mm}$ hailstones. For the $300 \mathrm{MPa}$ steel sheets of $0.35 \mathrm{~mm}$ in thickness shown in Figure 7, dents observed in two tests with the $40 \mathrm{~mm}$ hailstones were also observed to be larger than dents caused by the $45 \mathrm{~mm}$ hailstones. For the $0.55 \mathrm{~mm}$ thick steel sheets, the dent diameter was inversely proportional to the hailstone size. Hailstone used in the test 0.55/300/55 (5) did not shatter on impact. Although the hailstone did not shatter on impact with the steel sheet, resulting in a relatively large dent depth of $3.06 \mathrm{~mm}$, the dent diameter was not significantly affected. The dent diameter was $25.5 \mathrm{~mm}$, larger than the $21 \mathrm{~mm}$ diameter obtained from test $0.55 / 300 / 55$ (4). A comparison between $300 \mathrm{MPa}$ and $550 \mathrm{MPa}$ steel sheets of $0.35 \mathrm{~mm}$ thickness, shown in Figure 8, reveals that, on average, dent diameters of the $550 \mathrm{MPa}$ sheets were larger than the ones of the $300 \mathrm{MPa}$ sheets.

4.4. Comparison of Experimental Results with Theoretical Values. The increase of thickness resulted in a decrease in dent depth and diameter. An empirical equation correlation between the thickness and dent size was not developed due 


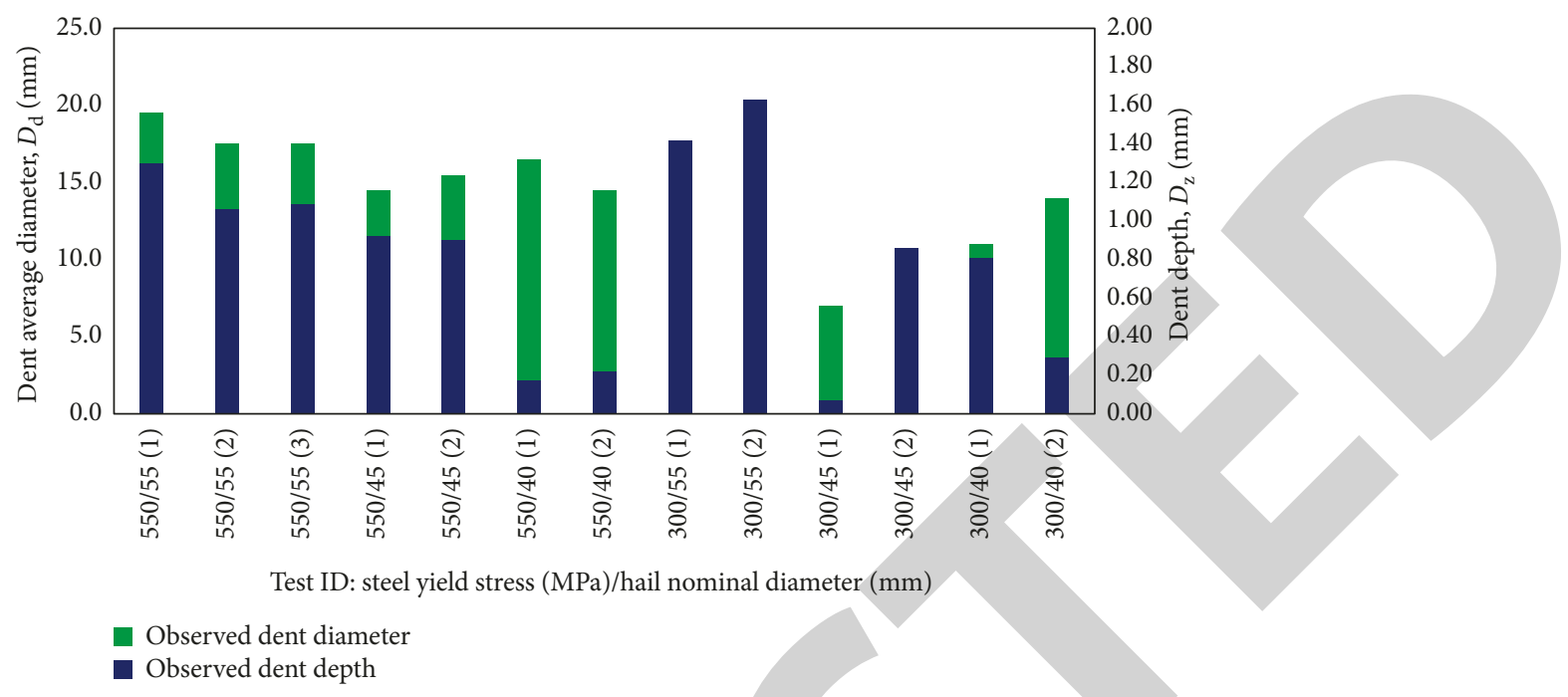

Figure 8: Dent depth and diameter for $0.35 \mathrm{~mm}$ steel samples having G550 and G300 grades.

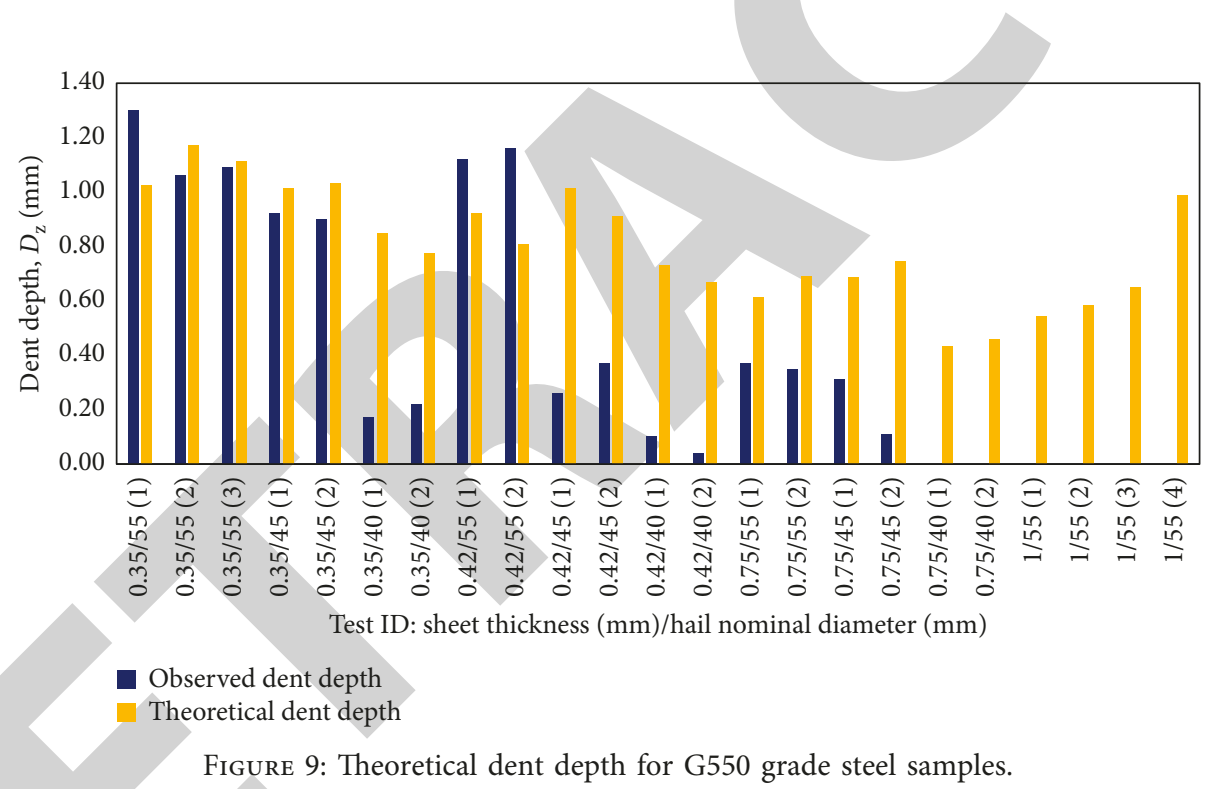

to the constraints of the study such as the limited sample amount, unknown hailstone behavior conditions, and the lack of tensile testing. It was found that visible denting has occurred for the steel sheets of $0.35 \mathrm{~mm}, 0.42 \mathrm{~mm}$, and $0.55 \mathrm{~mm}$ of thickness. Visible denting was obtained on the $0.75 \mathrm{~mm}$ steel sheets with the $45 \mathrm{~mm}$ and $55 \mathrm{~mm}$ hailstones; however, no denting was visible for the $40 \mathrm{~mm}$ hailstones. No denting was observed on the $1 \mathrm{~mm}$ steel sheets, irrespective of the use of $55 \mathrm{~mm}$ hailstone with $30 \mathrm{~m} / \mathrm{s}$ terminal velocity. Using the measured mass, velocity, and dent diameter for each test as shown in Table 5, the theoretical values of dent depth were determined. Nominal yield strength of the steel sheets was used for analysis as tensile testing was not available in the first revised manuscript. In this paper, the measured yield stresses given in Table 4 are now used for the theoretical and predicted calculations. The values reduced by $2 \%$ for the G300 steel sheets, while the values for the G550 sheets dropped to almost 12\% which made the estimation results better with the experimental results once the measured yield stresses were used in the theoretical and predicted calculations. Steel elastic modulus was taken as $200 \mathrm{GPa}$, and the coefficient of energy lost, $C_{\mathrm{e}}$, is taken to be 0.03 with the effect of high-speed camera although Bircan et al. [18] found that the value of $C_{e}$ was 0.20 based on the energy loss due to errors in the measurement of the velocity with laser sensors. The value of $C_{e}$ indicates that only $3 \%$ of the total hailstone kinetic energy is used for denting, assuming the theoretical expression is accurate. The nominal thicknesses for each sheet are verified to be same thickness as the nominal value provided. Results for the theoretical dent depths with their corresponding experiment results can be seen in Figures 9 and 10 .

In Figure 9, dent depths for all $550 \mathrm{MPa}$ steel sheets can be seen. For the $0.35 \mathrm{~mm}$ thickness, experiment results and theoretical values show good correlation for the $55 \mathrm{~mm}$ and $45 \mathrm{~mm}$ hailstones. Dent depths of the $0.35 \mathrm{~mm}$ thick steel 

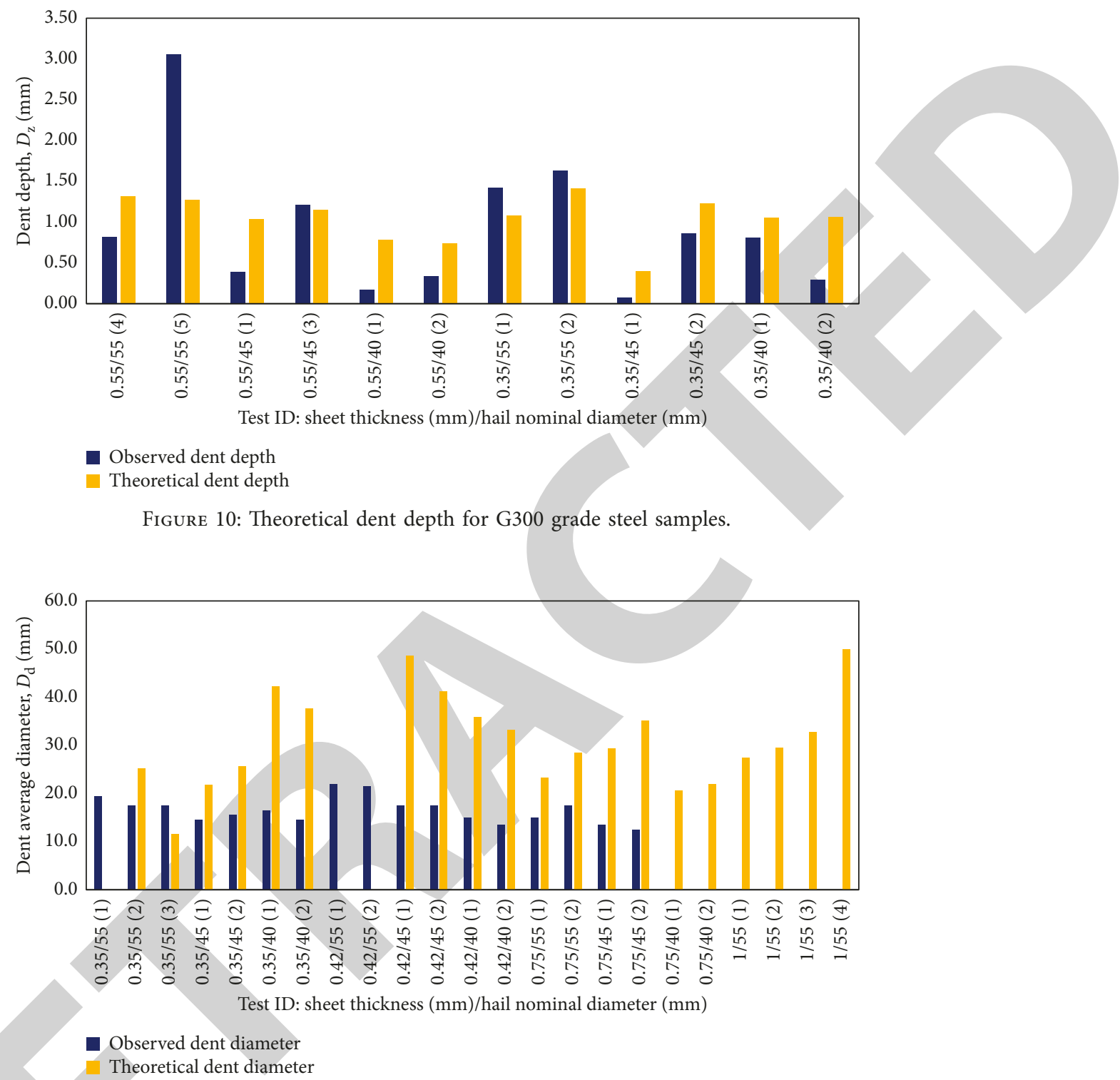

Figure 11: Theoretical dent diameters for G550 grade steel samples.

with the $40 \mathrm{~mm}$ hailstone were overestimated by the theory giving an experimental dent depth of $0.20 \mathrm{~mm}$. The theory also overestimated the dent depths of $0.42 \mathrm{~mm}, 0.75 \mathrm{~mm}$, and $1 \mathrm{~mm}$ steel sheets. For these tests, the denting either was either very small or nonexistent. In Figure 10, dent depths of the $300 \mathrm{MPa}$ steel sheets are shown. Theoretical values appear to follow the trend of the experiment results. However, just like the $550 \mathrm{MPa}$ steel sheets, the theory tends to overestimate low dent depths including tests $0.55 / 300 / 40$ (1), 0.55/300/40 (2), $0.35 / 300 / 45$ (1), and $0.55 / 300 / 40$ (2). The dent depth of test $0.55 / 300 / 55$ (5), where the artificial hailstone did not shatter on impact, was underestimated. A larger energy loss coefficient should be considered for this case. When the test results gave dent depth below $0.75 \mathrm{~mm}$, an accurate estimation could not be achieved with the expression in equation (11). Otherwise, the expression tends to follow the trend and give a good estimation of the dent depth.
The results are shown in Figures 11 and 12. Unlike the dent depth, theoretical values of the dent diameter do not correlate well with experimental results. In most cases, the theoretical dent diameter is over twice as large as their corresponding experimental values. Furthermore, for the tests $0.35 / 550 / 55$ (1), 0.42/550/55 (1), and 0.42/550/55 (2), invalid results were obtained as a negative value appeared within the square root of the equation. Again, the theory fails to deliver accurate results for the cases where no dent was observed. In Figure 11, it can be seen that the theory overestimated the dent diameters for the $300 \mathrm{MPa}$ steel sheets in similar manner with the $550 \mathrm{MPa}$ steel sheets. For $300 \mathrm{MPa}$ steel sheets, theoretical values were over three times larger than experimental results. It can also be seen that the theoretical results of tests $0.55 / 300 / 55$ (5), 0.55/300/45 (3), $0.35 / 300 / 55$ (1), and $0.35 / 300 / 55$ (2) were invalid, as given in Figure 12. 

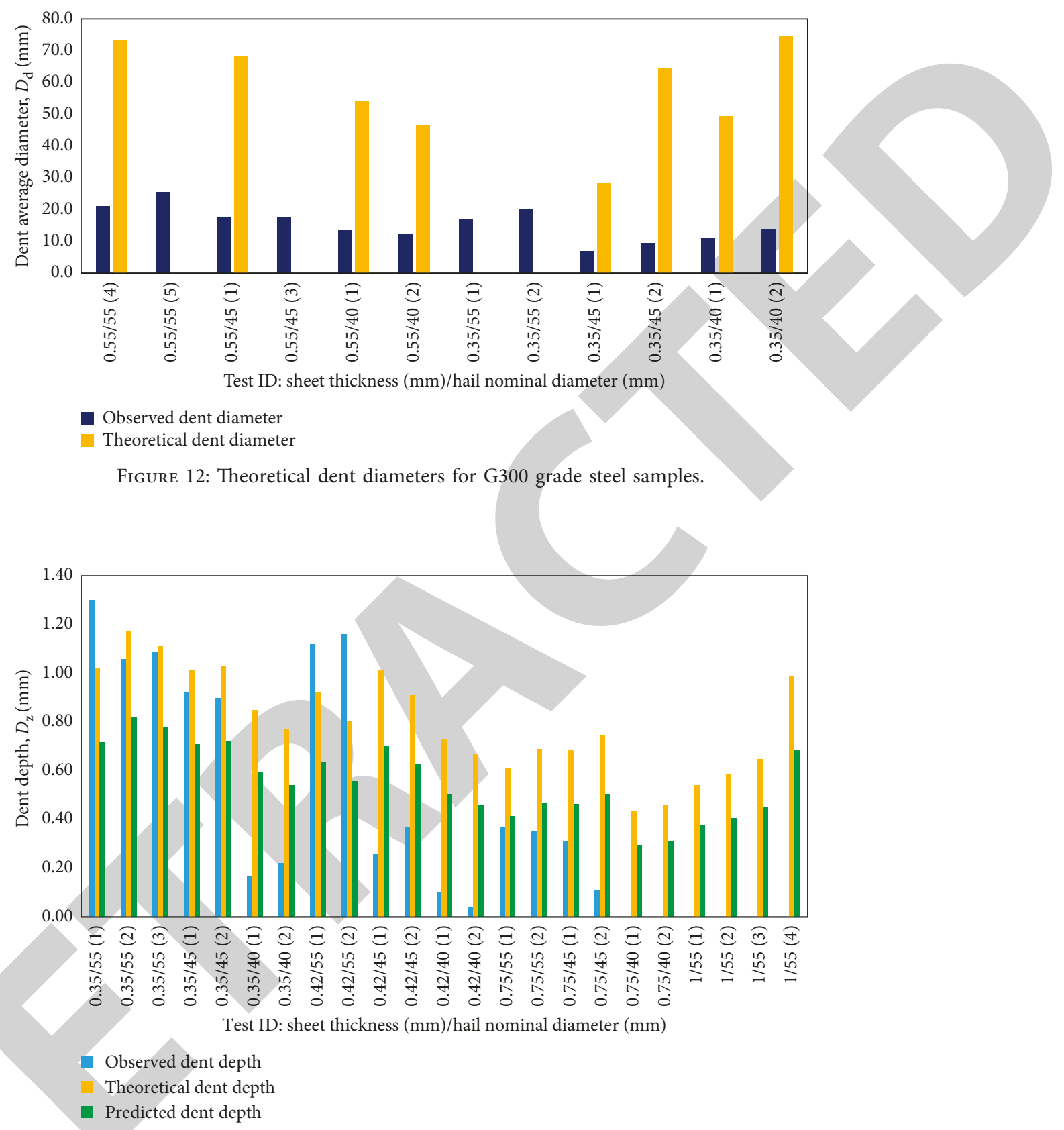

Figure 13: Predicted dent depth for G550 steel samples.

4.5. Comparison of Experimental Results with Predicted Values. A limitation of equations (11) and (12) is that either dent depth or dent diameter must be known to determine the other. For this reason, the theory is not useful for predicting the dent depth or the diameter before the impact. This limitation was addressed with the development of equation (13). By applying a further assumption that $D_{\mathrm{d}} / D_{\mathrm{z}}$ is a constant value, the dent depth can be predicted for a given steel sheet under impact of a given hailstone at its terminal velocity. The average value of $D_{\mathrm{d}} / D_{\mathrm{z}}$ was taken as 52 from the data collected. The predicted, theoretical, and observed dent depths are compared in Figures 13 and 14. In Figure 13, the predicted dent depths for the $550 \mathrm{MPa}$ steel sheets are very similar to theoretical values given in all tests.
The predicted values are accurate for the $0.35 \mathrm{~mm}$ thick steel sheet for the $45 \mathrm{~mm}$ and $55 \mathrm{~mm}$ hailstones. Similar to theoretical dent depth values, predicted dent depth values were not accurate for depths less than $0.75 \mathrm{~mm}$. Inaccuracy is particularly visible for tests with $0.75 \mathrm{~mm}$ and $1.00 \mathrm{~mm}$ thick steel sheets. In Figure 14, the predicted dent depths for the $300 \mathrm{MPa}$ steel sheets appear to be consistent with theoretical values, similar to the $550 \mathrm{MPa}$ steel sheets. For all $300 \mathrm{MPa}$ sheets, the all predicted dent depths were either equal to or slightly lower than theoretical values.

4.6. Determination of the $D_{d} / D_{z}$ Parameter. The value of $D_{\mathrm{d}} / D_{\mathrm{z}}$ was assumed to constant, and an average of 52 was 


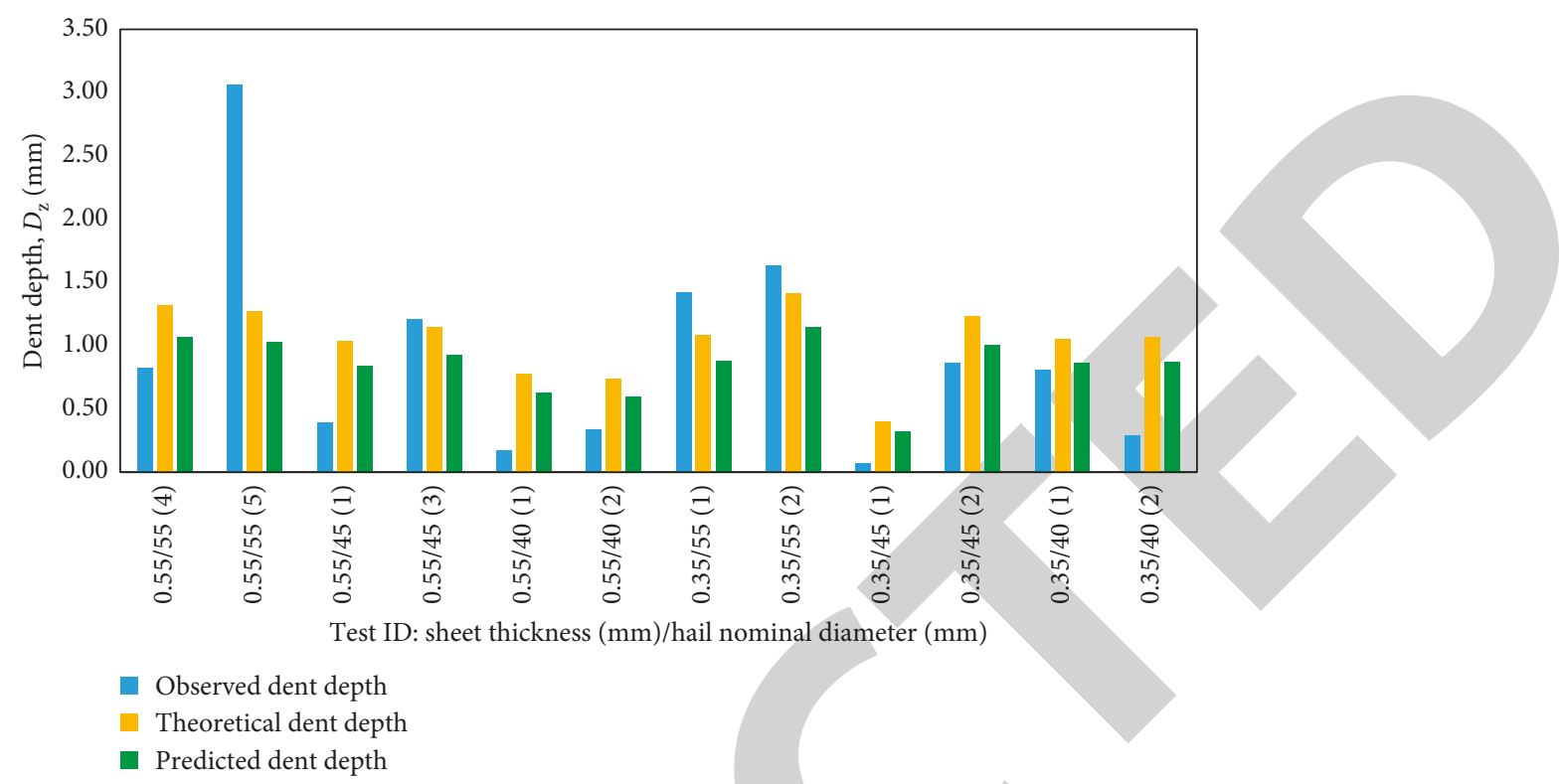

Figure 14: Predicted dent depth for G300 steel samples.

used. Experimental results of dent depth, $D_{\mathrm{d}}$, and dent diameter, $D_{\mathrm{z}}$, were used to create Table 6. Despite that $D_{\mathrm{d}} / D_{\mathrm{z}}$ was assumed to be constant and 52 , the value can be between 8 and 338. While the assumption of a constant value is not true, its results are satisfactory when compared to theoretical values. In Figures 15 and 16, equation 13 has low sensitivity regarding the $D_{\mathrm{d}} / D_{\mathrm{z}}$ factor. In Figure 15, the predicted dent depths are for the $D_{\mathrm{d}} / D_{\mathrm{z}}$ value of 8 . The predicted dent depth was increased by $5 \%$ in most cases. The predicted dent depths are given in Figure 16 for the $D_{\mathrm{d}} / D_{\mathrm{z}}$ value of 100 . The predicted dent depth has reduced by $20 \%$ in most cases. Due to the low sensitivity of equation 13 to the $D_{\mathrm{d}} / D_{\mathrm{z}}$ value over a large range, it is believed to be acceptable to take its value as 8. This is strongly supported by the strong consistency achieved with theoretically determined dent depths. Although the ratio of dent diameter to dent depth is required as an input, the result was found to be not very sensitive to this input value. Plot of $D_{\mathrm{d}}$ against $D_{z}$ is given in Figure 17. It can be seen that the slope is close to flat with the increasing value of $D_{z}$.

\section{Conclusions}

The experiment conducted in the study examined hailstones of varying diameters and impact velocity striking steel sheets of varying yield stresses and thickness. All artificial hailstones but one shattered upon impact. The hailstone that remained intact caused a dent with a depth twice as higher as the second largest dent depth observed. This is due to a higher proportion of kinetic energy being transferred to the steel sheet, instead of transferring energy to the dispersing fractures. It should be noted that natural hailstones commonly bounce off surfaces and remain intact. Without fracturing, the coefficient of energy loss can be assumed to be higher than 0.03 used in analysis. There were some
TABLe 6: $D_{\mathrm{d}} / D_{\mathrm{z}}$ for all tests.

\begin{tabular}{|c|c|}
\hline Test & $D_{\mathrm{d}} / D_{\mathrm{z}}$ \\
\hline $0.35 / 550 / 55(1)$ & 15 \\
\hline $0.35 / 550 / 55(2)$ & 17 \\
\hline $0.35 / 550 / 55(3)$ & 16 \\
\hline $0.35 / 550 / 45(1)$ & 16 \\
\hline $0.35 / 550 / 45(2)$ & 17 \\
\hline $0.35 / 550 / 40(1)$ & 97 \\
\hline $0.35 / 550 / 40(2)$ & 66 \\
\hline $0.42 / 550 / 55(1)$ & 20 \\
\hline $0.42 / 550 / 55(2)$ & 19 \\
\hline $0.42 / 550 / 45(1)$ & 67 \\
\hline $0.42 / 550 / 45(2)$ & 47 \\
\hline $0.42 / 550 / 40(1)$ & 150 \\
\hline $0.42 / 550 / 40(2)$ & 338 \\
\hline $0.75 / 550 / 55(1)$ & 41 \\
\hline $0.75 / 550 / 55(2)$ & 50 \\
\hline $0.75 / 550 / 45(1)$ & 44 \\
\hline $0.75 / 550 / 45(2)$ & 114 \\
\hline $0.75 / 550 / 40(1)$ & - \\
\hline $0.75 / 550 / 40(2)$ & - \\
\hline $1.00 / 550 / 55(1)$ & - \\
\hline $1.00 / 550 / 55(2)$ & - \\
\hline $1.00 / 550 / 55(3)$ & - \\
\hline $1.00 / 550 / 55(4)$ & - \\
\hline $0.55 / 300 / 55(4)$ & 26 \\
\hline $0.55 / 300 / 55(5)$ & 8 \\
\hline $0.55 / 300 / 45(1)$ & 45 \\
\hline $0.55 / 300 / 45(3)$ & 14 \\
\hline $0.55 / 300 / 40(1)$ & 79 \\
\hline $0.55 / 300 / 40(2)$ & 37 \\
\hline $0.35 / 300 / 55(1)$ & 12 \\
\hline $0.35 / 300 / 55(2)$ & 12 \\
\hline $0.35 / 300 / 45(1)$ & 99 \\
\hline $0.35 / 300 / 45(2)$ & 11 \\
\hline $0.35 / 300 / 40(1)$ & 14 \\
\hline $0.35 / 300 / 40(2)$ & 48 \\
\hline
\end{tabular}




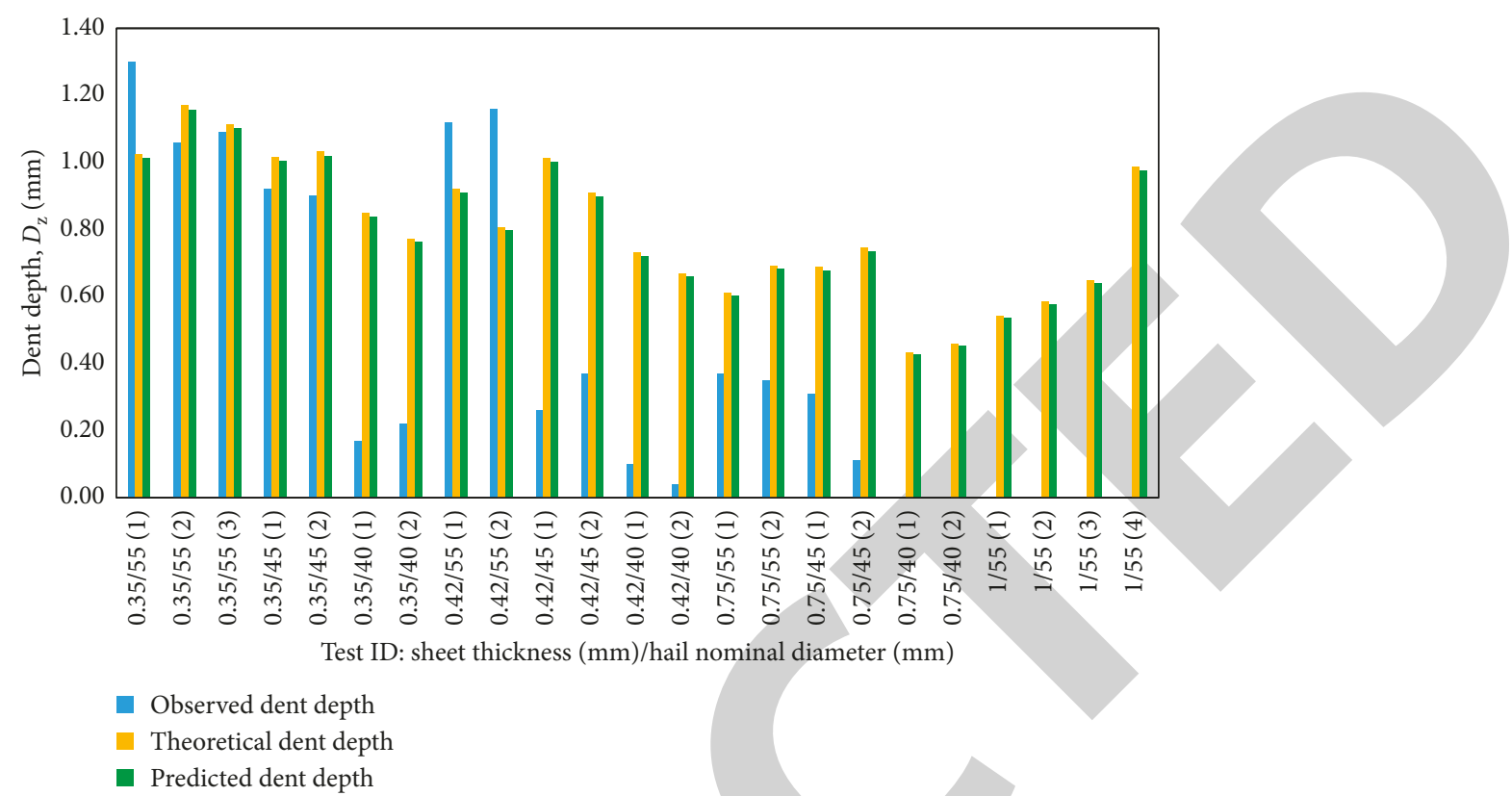

Figure 15: Predicted dent depth with $D_{\mathrm{d}} / D_{\mathrm{z}}$ of 8 for G550 steel sheets.

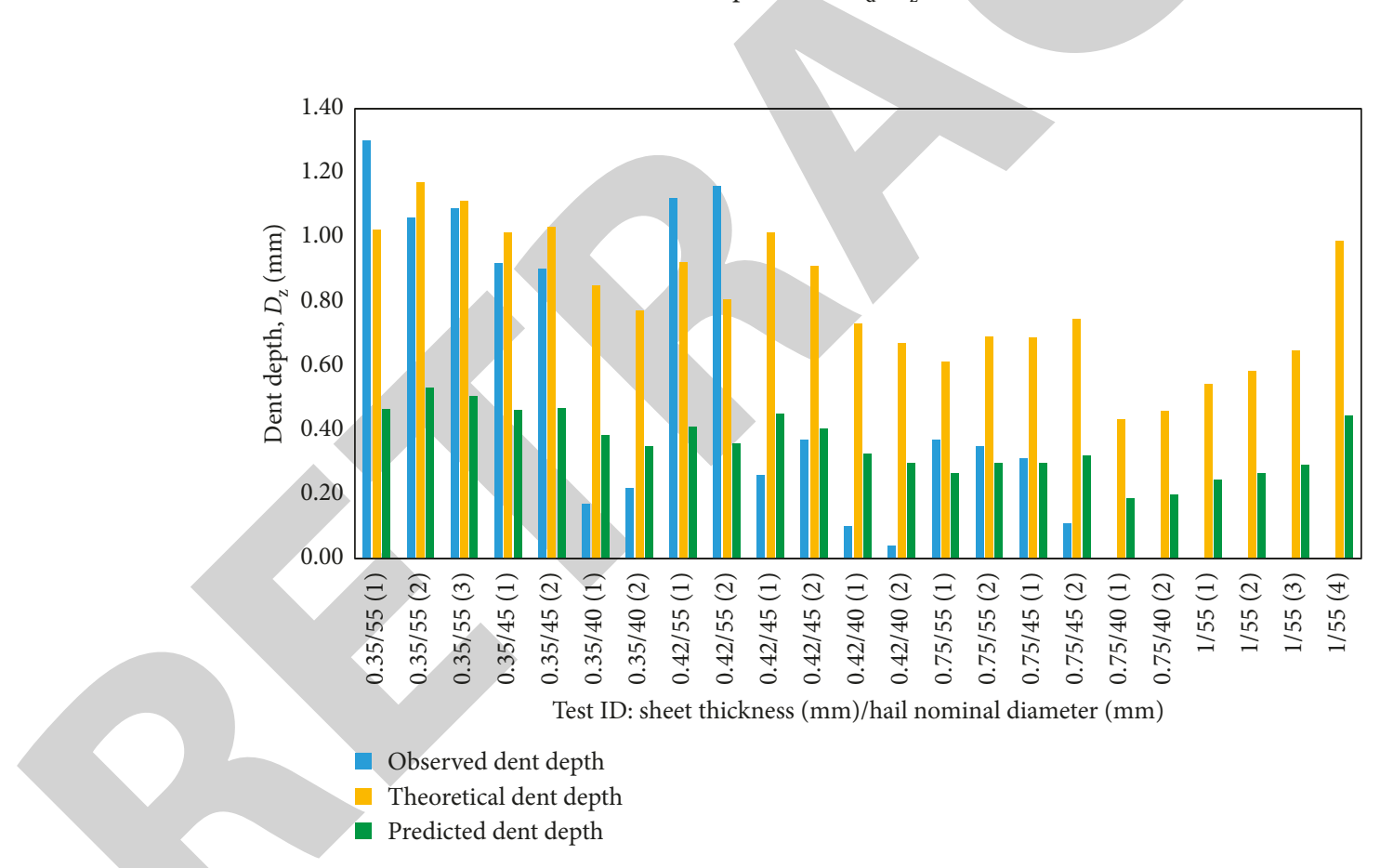

Figure 16: Predicted dent depth with $D_{\mathrm{d}} / D_{\mathrm{z}}$ of 100 for G550 steel sheets.

unexpected trends. For example, increasing yield stress resulted in an increased dent diameter. It was found that $40 \mathrm{~mm}$ hailstones caused larger dent diameters than $45 \mathrm{~mm}$ hailstones with the same impact velocity. As the yield stress of the steel sheet increased, the dent depth decreased for G300 and G550 steel. The dent diameter however increased as the yield stress increased. With the first expression, the theory failed to model dent depths below $0.75 \mathrm{~mm}$ or the absence of denting. This was caused by assumptions made to develop the expressions. The second expression overestimates the dent diameter by a significant factor. The theoretical values were over three times as large for $550 \mathrm{MPa}$ steel sheets and over twice as large for $300 \mathrm{MPa}$ steel sheets. This expression is unsuitable for application. The third expression, for a given unknown dent diameter, has predicted the dent depth values that align well with theoretical values obtained from first expression. Using the measured yield stresses for each steel sheet results, a decrease is seen slightly in the theoretical calculations as the measured yield stresses are higher than the nominal ones, especially in the G550 steel sheet with the thickness of $0.75 \mathrm{~mm}$. Although the ratio of dent diameter to dent depth is required as an input, 


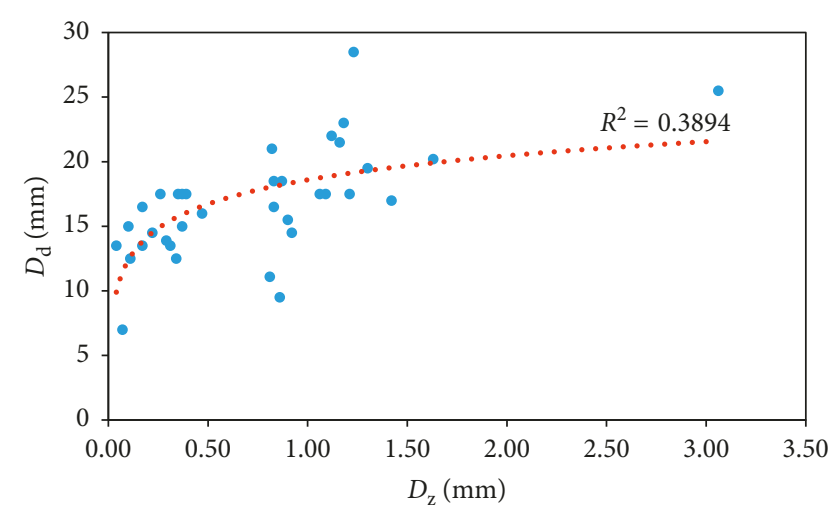

Figure 17: Correlation of $D_{\mathrm{d}}$ against $D_{\mathrm{z}}$.

the result was found to be not very sensitive to this input value. Using a lowest value of 8 in $C_{e}$ gave results that aligned well with theoretical results. But this expression also failed to model dents of $0.75 \mathrm{~mm}$ in depth or the absence of a dent. The indentation results of the pure clear ice balls obtained from this manuscript will be validated against those of artificial hailstones that happened to remain intact after impact at similar velocities in future studies.

\section{Data Availability}

The Excel data used to support the findings of this study are available from the corresponding author upon request.

\section{Conflicts of Interest}

The author declares that there are no conflicts of interest.

\section{Acknowledgments}

The author would like to thank Vice-Chancellor and Dean Prof. Halil Kirnak at Aydin Adnan Menderes University for providing a laboratory environment for this work and my bachelor students Ms. Dilara Kop and Mr. Mehmet Goren, my previous master student (unfinished) Mr. Ibrahim Ozturk at Adnan Menderes University, and my previous students Mr. Talha Bircan and Mr. Eren Erdem at Izmir Institute of Technology for helping me for the set-up.

\section{References}

[1] Australian Building Codes Board, "An investigation of possible building code of Australia (BCA) adaptation measures for climate change," Australian Government Report, Australian Building Codes Board, Canberra, Australia, 2010.

[2] Emergency Management Australia, "Community development in recovery from disaster (manual 29)," in Emergency Management Australia Canberra, ACT, Hyderabad, Telangana, 2003.

[3] Bureau of Meteorology, Severe Thunderstorms [Electronic Resource]: Facts, Warnings and Protection, PANDORA Electronic Collection, Melbourne, Australia, 2009.

[4] L. M. Leslie, M. Leplastrier, and B. W. Buckley, "Estimating future trends in severe hailstorms over the Sydney Basin: a climate modelling study," Atmospheric Research, vol. 87, no. 1, pp. 37-51, 2008.

[5] CSIRO and The Bureau of Meteorology, "Climate Change in Australia," Technical Report, CSIRO and The Bureau of Meteorology, Aspendale, Victoria, Australia, 2007.

[6] J. Bengtsson, R. Hargreaves, and I. C. Page, Assessment of the Need to Adapt Buildings in New Zealand to the Impacts of Climate Change, BRANZ, Wellington, New Zealand, 2007.

[7] D. Moore and A. Wilson, Photovoltaic Solar Panel Resistance to Simulated Hail, Low-Cost Solar Array Project, California Institute of Technology, Pasadena, CA, USA, 1978.

[8] J. D. Rhymer, Force Criterion Prediction of Damage for Carbon/Epoxy Composite Panels Impacted by High Velocity Ice, University of California, San Diego, CA, USA, 2012.

[9] M. E. Uz, L. Teh, and J. Maguire, "Developing australian's first hali-proof roofing profiles," in Sustainable Building Research Center Open Day 2014 (SBRC), University of Wollongong, Wollongong, Australia, 2014.

[10] S. Dunlop, A Dictionary of Weather, Oxford University Press, New York, NY, USA, 2nd edition, 2008.

[11] P. Engelbert, The Complete Weather Resource, UXL, Detroit, MI, USA, 1997.

[12] J. C. Brimelow, T. W. Krauss, and G. W. Reuter, "Operational forecasts of maximum hailstone diameter," Journal of Weather Modification, vol. 34, pp. 8-17, 2002.

[13] J. Sun, N. Lam, L. Zhang, D. Ruan, and E. Gad, "Contact forces generated by hailstone impact," International Journal of Impact Engineering, vol. 84, pp. 145-158, 2015.

[14] V. Crenshaw and J. D. Koontz, Hail: Sizing It up!, Western Roofing Magazine, Reno, NV, USA, 2002.

[15] J. A. P. Laurie, "Hail and its effects on buildings," Research Report, NBRI, Pretoria, South Africa, 1960.

[16] E. P. Lozowski and G. S. Strong, "Further reflections on the calibration of hailpads," Atmosphere-Ocean, vol. 16, no. 1, pp. 69-80, 1978.

[17] M. Uz, G. Yilmaz, and T. Bircan, "The making of a hailstone simulated realistic damage," Journal of Engineering Sciences and Design, vol. 5, no. 2, pp. 411-423, 2017.

[18] T. Bircan, M. Uz, H. Kirnak, E. Erdem, M. Goren, and D. Kop, "Investigation of a theory for determining hailstone resistance," in Proceedings of the 13th International Congress on Advances in Civil Engineering, Izmir, Turkey, September 2018.

[19] C. Burley, B. Niemeier, and G. Koch, Dynamic Denting of Autobody Panels, Society of Automotive Engineers, Detroit, MI, USA, SAE No. 760165, 1976.

[20] T. N. Seel, Bake Hardening Steel Application Study-Key Factors of Dent Resistance Improvement, Society of Automotive Engineers, Detroit, MI, USA, 1991.

[21] S. Holmberg and P. Thilderkvist, "Influence of material properties and stamping conditions on the stiffness and static dent resistance of automotive panels," Materials \& Design, vol. 23, no. 8, pp. 681-691, 2002.

[22] M. F. Shi et al., An Evaluation of the Dynamic Dent Resistance of Automotive Steels, Society of Automotive Engineers, Detroit, MI, USA, SAE No. 970158, 1991.

[23] J. Maguire, "Experimental determination of the effects of hail impact on steel building envelopes," in Civil, Mining and Environmental Engineering, pp. 1-108, University of Wollongong, Wollongong, Australia, 2014.

[24] D. C. Chang and R. P. Khetan, "Surface damage of steel, aluminum, and chopped-fiber composite panels due to projectile impact," Journal of Reinforced Plastics and Composites, vol. 3, no. 3, pp. 193-203, 1984. 
[25] J. D. Tippmann, Development of a Strain Rate Sensitive Ice Material Model for Hail Ice Impact Simulation, University of California, San Diego, CA, USA, 2011.

[26] B. A. Niemeier and C. E. Burley, Hailstone Response of Body Panels-Real and Simulated, SAE International, Warrendale, PA, USA, 1978.

[27] H. Kim, D. A. Welch, and K. T. Kedward, "Experimental investigation of high velocity ice impacts on woven carbon/ epoxy composite panels," Composites Part A: Applied Science and Manufacturing, vol. 34, no. 1, pp. 25-41, 2003.

[28] R. Juntikka and R. Olsson, "Experimental and modelling study of hail impact on composite plates," in Proceedings of the International Conference on Composites Materials (ICCM), vol. 17, Edinburgh, Scotland, July 2009. 